\title{
Hazard from blasting fumes in normal rock tunnelling with particular reference to nitrogen dioxide
}

\author{
by \\ C. A. Fogden, M.A., M.I.C.E. \\ and \\ A. D. Garrod, B.Sc., D.I.C., A.M.I.C.E.
}

Dr D. E. Wright (Lecturer in Civil Engineering, Imperial College, formerly Assistant Engineer, Messrs Binnie and Partners) wrote that the Authors, under whom he had worked on the Telom and Habu tunnels mentioned in the Paper, were to be congratulated on organizing the collection and presentation of fresh data on this somewhat unusual problem. In common with most new investigations the Paper suggested further unfulfilled lines of research and the writer hoped that it would stimulate others associated with tunnelling works to fill out and confirm the information presented. There was evidently a paucity of data on this important aspect of tunnelling work.

44. He first wished to comment on a few matters arising directly from the text.

45. Did the Authors know the total number of casualties $(\S 1)$ and if so what was the proportion of these to the total number of exposures? Was there any common factor in the fatal cases?

46. There appeared to be some contradiction between the statement in $\S 6$ that 'the intense irritation . . . is the . . immediate effect of inhalation ...' and that in $\$ 7$ 'the slight inconvenience it causes . . . is out of all proportion to the irritation ... it gives rise to later . . . W Was this apparent divergence of view an expression of the uncertainty of medical opinion on the physiological effects of exposure to nitrogen dioxide? From his personal experience the writer would definitely say that the effects were very immediate and most unpleasant, the severe headache caused by inhalation often lasting for the rest of the day.

47. The writer presumed that the area used in the formula given in $\S 15$ was that of the actual excavated area, since what was required was the actual volume of $\mathrm{NO}_{2}$ released by a known quantity of explosive. Had these volumetric results been corrected to allow for the $3500 \mathrm{ft}$ difference in elevation between the Telom (and Habu) and Woh tunnels? Was there any particular advantage to be gained in working in terms of volume rather than mass?

48. Was the chemical composition of explosives a sufficiently variable factor to make it important to know the constituents of those used in these tests? If so, could the Authors give this information?

49. It was necessary to plot the total nitrogen dioxide concentrations as a check on the known danger levels, as the Authors had done in Figs 1 to 6, but for comparative purposes was not this better expressed per pound of explosive? The actual charge used was rarely the same from one round to another.

50. It appeared from the data given in Appendices 1 and 2 that the velocity of the fume plug used in calculating the volume of nitrogen dioxide $(\$ 15)$ was determined by dividing the distance between the face and sampler point by the time taken by the

- Proc. Insin civ Engrs, 1965, 31 (July), 257-282. 
fumes to reach peak concentration at the sampler point. In all tunnels there were leaks in the ventilation duct (in the case of Telom only $37.5 \%$ of the inducted air reached the face when the tunnel was $20000 \mathrm{ft}$ long), and this meant that the velocity of return air flow, and, by supposition, the velocity of the fume plug itself, gradually increased towards the portal. Thus the actual fume plug velocity at any point was necessarily greater than the average velocity calculated according to the assumption above. This fact would not greatly affect the Authors' results as, with one exception, they were all obtained from points between $900 \mathrm{ft}$ and $1400 \mathrm{ft}$ from the face, where the difference in actual and average velocities was negligible. However, when processing the data obtained over a long length of tunnel this was a point to be considered, as errors in velocity of the order of $60 \%$ would be involved in tunnels $20000 \mathrm{ft}$ long having ventilation duct leaks similar to Telom.

51. Turning to matters of more general concern, in $\$ 2$ it was stated that the casualties were generally confined to the men working away from the face, and it seemed to the writer that it was these men who stood to gain the most from advances in knowledge and technique. It was therefore important to know how the plug of fume attenuated during its passage through the tunnel. In the short time available to them the Authors had not been able to collect data which would enable a comprehensive plot of nitrogen dioxide volume and peak concentration to be made over a considerable distance from the face, although the data plotted in Fig. 7 appeared to show that near the face the nitrogen dioxide volume decreased over a comparatively short distance (even when water sprays were not operating). It was hard to see how different ventilation rates could cause a reduction in total gas volume and the writer presumed that chemical factors were responsible for the decrease. Had the Authors any comment on this? It would obviously be of value to have more information from tunnels now under construction and such data might be backed by laboratory experiments designed to investigate the variation of fume plug velocity, volume and peak concentration over considerable distances at different ventilation rates.

52. The Paper drew attention to yet another set of circumstances in which the conflicting demands of safety on the one hand and economy on the other had to be resolved. There was clearly no doubt that, in principle, an atmosphere clear of dangerous fume concentrations should be provided for tunnel workers, but as the Authors showed in $\$ 30$ to 32, there was no one obvious solution. The problem of space became acute in long, relatively small tunnels like the Telom. Promoters would have to realize that increased standards of safety would inevitably tend to increase costs.

Mr J. D. Lawrence (Assistant Engineer, Messrs Binnie and Partners, formerly Resident Engineer, Preliminary Contracts, Batang Padang Hydro-Electric Scheme) wrote that he considered himself fortunate to have taken part in the investigations carried out in the preparation of the Paper. The Authors were to be complimented on a most interesting Paper which made a definite contribution to a subject which was often apt to be taken for granted.

54. The specification for ventilation of underground works for the main Batang Padang Scheme was based on the experience of the Authors. The writer was in the useful position of being able to compare the conditions in the Woh trial tunnel with those in the early stages of the excavation of the Lower Menglang tunnel, of almost the same cross section as the Woh tunnel, and at the time of writing (August, 1965) of similar length. It was, however, some $1100 \mathrm{ft}$ higher in elevation and the prevalent temperatures were about $5^{\circ} \mathrm{F}$ lower.

55. Forced ventilation was used to supply air continuously to the face, the minimum quantity being assessed on the basis of the cross-sectional area. In addition, a separate exhaust system was installed which it was intended should be switched on immediately after each blast, to remove the fumes. 


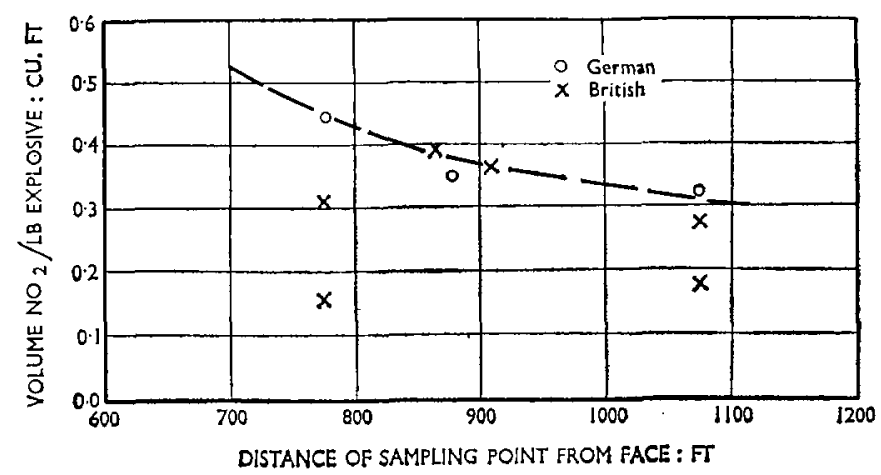

Fig. 11: COMPARISON OF AMOUNTS OF GAS LIBERATED

56. In the Telom and Woh tunnels the forced ventilation air supply at the face was below most of the minima as assessed by the standards given in Table 2 . In the Menglang tunnel, although at the time of writing actual measurements of the airflow in the tunnel had not been made, it was apparent that the air supply was probably in excess of the minimum. It had in fact been found that the exhaust ventilation was often unnecessary, the forced ventilation being good enough to disperse the fumes sufficiently to prevent undue discomfort to workers anywhere in the tunnel. These were the conditions when the duct length was 5000 to $6000 \mathrm{ft}$. The maximum length would be much greater, and the need for exhaust ventilation would increase as the length of duct and the losses in it increased.

57. These observations applied equally to blasting operations carried out with $60 \%$ and $90 \%$ gelatine of British, German and Canadian manufacture, and to A.N.F.O. explosives, all of which had been used.

58. The Authors pointed out the errors which could occur in calculations based on the plotted results. However, Mr Lawrence was of the opinion that the conclusion drawn in $\S \S 3(\mathrm{e})$ and 16 with regard to the larger quantity of gas released by explosive of German manufacture might be misleading. What was perhaps overlooked was that there was a natural dissipation of liberated nitrogen dioxide, both in peak concentration and in quantity, as a fume plug passed down the tunnel. A plot of the volume of gas liberated/lb of explosive used against the distance of the sampling point from the face would always show that the quantity reduced as the distance increased. In practice the curve was probably hyperbolic. Such a plot for tests $9,10,12,14(\mathrm{a})$, 15(a) and 16(a) showed that there was virtually no difference in the quantities of gas liberated by the two types of explosive (Fig. 11).

59. Referring to Fig. 7, Mr Lawrence concluded that the effect of water sprays became negligible at 1200 to $1300 \mathrm{ft}$ from the face. The main point was that at 1200 to 1300 (or 1500 ) ft from the face the same amount of nitrogen dioxide would have been absorbed naturally without a spray as was absorbed by the spray. Several of the accidents which occurred on the Cameron Highlands Scheme took place at distances from the face greater than $1500 \mathrm{ft}$. The conclusion was therefore that sprays would not be effective in preventing accidents.

60. There was obviously much scope for further work in this field. However, the work already done was sufficient to illustrate the importance of efficient ventilation. It was perhaps regrettable that the rapid improvement of modern tunnelling methods might itself discourage further costly and time-consuming research. 
Mr F. D. B. Forster (Senior Engineer, Edmund Nuttall, Sons \& Co. (London) Ltd) wished to congratulate the Authors on producing a most interesting Paper.

62. The writer was employed as Agent on the driving of the Main Tunnel of the North of Scotland Hydro-Electric Board's Breadalbane Project (Killin Section). The tunnel was of 14-ft horseshoe section and about 5 miles long. A shaft intake some $7000 \mathrm{lin}$. $\mathrm{ft}$ from the downstream end was used for tunnel ventilation on the longest heading after driving had passed that point, the ventilation blowers being moved up the tunnel to the foot of the shaft. Driving continued for $10000 \mathrm{lin}$. $\mathrm{ft}$ beyond this point before junctioning took place with the downstream drive.

63. The explosive used was Polar Ammon Gelignite, manufactured by the largest British manufacturer, some $140 \mathrm{lb}$ being used per round. During the carrying out of this work there were no cases in either of the headings of men being affected by blasting fumes, and it might be of interest to give details of the ventilation system used.

64. The ducting of 15 -in. diameter piping was kept within about $100 \mathrm{ft}$ of the working face and was connected at the outer end to a Godfrey Type P.4000 industrial Blower giving $3000 \mathrm{cu} . \mathrm{ft} / \mathrm{min}$ at $2900 \mathrm{rev} / \mathrm{min}$, driven by a $90 \mathrm{hp}$ electric motor. Also in the circuit, in parallel, was a Connersville Positive Rotary Blower giving $2000 \mathrm{cu}$. $\mathrm{ft} / \mathrm{min}$ at $400 \mathrm{rev} / \mathrm{min}$, driven by a $40 \mathrm{hp}$ electric motor.

65. The procedure adopted after blasting was to run the Godfrey Blower on blowing into the tunnel for $\mathbf{2 0}$ minutes and then to reverse, so that it was sucking air out through the ducting for the next 20 minutes. After that the Godfrey Blower was switched off and the Connersville Rotary Blower was switched into the circuit, and this continued to suck air out for the rest of the cycle. All the plant used was either electrically or pneumatically driven, and so the problem of ventilation consisted mainly of dealing with blasting fumes.

66. The writer believed that an accepted rule of thumb for Great Britain was to allow $150 \mathrm{cu}$. ft/min of free air per man, or (when diesel plant was used) $80 \mathrm{cu} . \mathrm{ft} / \mathrm{min}$ per hp, whichever was the higher.

67. From the Paper it appeared that the south heading of the Telom tunnel was more than $20000 \mathrm{ft}$ long, that air was blown into the tunnel through ducting, and that the fumes were blown down the tunnel. From past experience the writer would have thought that it would have been preferable to have a series of booster fans sucking the fumes out through the ducting, as this would have avoided 'plugs' of blasting fumes in the tunnel. These could be most objectionable and were difficult to disperse. They appeared to have increased the hazard from blasting fumes and to have been a contributory cause of the fatalities.

Mr O. A. Gurton (Imperial Chemical Industries Limited, Nobel Division, Explosives Research) wrote that the Paper was of considerable interest to miners and hard rock tunnellers. It gave a concise review of knowledge concerned with toxic fumes produced in blasting and provided valuable additional information in reporting the results of a thorough practical examination.

69. Nitrogen dioxide concentration diminished with time not only because of natural diffusion but also because this gas was highly reactive and easily absorbed by dust and mist particles. The total quantity therefore fell off with time and the rate of loss of nitrogen dioxide was proportional to the concentration of this substance. This fact helped to explain why fume plugs near to rounds of explosive contained proportionally higher amounts of nitrogen dioxide than fume plugs further away. The carbon monoxide produced by detonation of an explosive did not decay in the same way.

70. From the values of carbon monoxide concentration listed in the Paper it was possible to calculate that the explosives produced between 0.5 and $0.6 \mathrm{cu}$. $\mathrm{ft} / \mathrm{lb}$. In laboratory tests and in some controlled trials in a fireclay mine, a similar explosives yield between 0.25 and $0.4 \mathrm{cu}$. $\mathrm{ft} / \mathrm{lb}$ of carbon monoxide had been found. Although these figures were lower than those of the Authors they were of the same order. 
Results for the yield of nitrogen dioxide $(0 \cdot 15-0.4 \mathrm{cu} . \mathrm{ft} / \mathrm{lb})$ were also of the same order as the yields quoted in Appendix 2 of the Paper but referred to the immediate yield of nitrogen dioxide and were calculated by allowing for the loss of the gas with time. The yields of nitrogen dioxide referred to in the Paper were therefore in general considerably higher than would have been expected. High nitrogen dioxide yields could be caused by any conditions which prevented the explosive from doing all the work of which it was capable. Very wet conditions, inadequate stemming and overcharging all tended to increase the production of $\mathrm{NO}_{2}$. In the writer's experiments in a fireclay mine the conditions were dry, good stemming was used and the charges were well balanced to the work they had to do. In practical hardrock tunnelling such ideal conditions might be difficult to maintain.

Mr E. Hill (Agent for Edmund Nuttall, Sons \& Co. (London) Ltd, at the Cruachan Hydro-Electric Scheme) wrote that he was pleased to have the opportunity of taking part in the discussion as his firm had been involved in somewhat similar ventilation problems at Cruachan.

72. The Authors' excellent investigation on gas analysis went far beyond what they had done, possibly because there had not been any accidents of the type described. In fact there were only a very small number of gassing accidents due to explosives reported in Britain over the last 10 years,* and these were attributable either to incomplete detonation causing burning of the explosive or to poor ventilation. It would be interesting to know if the Authors had any evidence of poor or incomplete detonation occurring during the operations covered in the Paper.

73. At Cruachan the chief concern had been with carbon monoxide from diesel exhaust fumes. The utmost priority was given to the driving of a ventilation shaft in the central part of the workings, but before this was completed a large forced ventilation system was installed. For every horse power of plant working in the tunnel $80 \mathrm{cu}$. $\mathrm{ft}$ of $\mathrm{air} / \mathrm{min}$ was provided. It was the practice for a senior engineer to take air samples in various parts of the tunnel several times in each shift. When the carbon monoxide content approached dangerous levels the number of diesel units allowed to work was reduced until a satisfactory level was achieved. Oxycatalyst exhaust scrubbers were fitted to the loading tractors and these had a marked effect in reducing the carbon monoxide content of the exhaust fumes. Air testing was done with the Siebe Gorman Potassium Pallado Sulphite CO Detector. It would be interesting to know the amount of diesel plant working in the Cameron Highland tunnels and what levels of carbon monoxide were found, particularly near any stationary plant.

74. The Authors' figures for $\mathrm{NO}_{2}$ concentrations from the two explosive types appeared to favour that of British manufacture. This might not be as significant as it appeared. These explosives were physical mixtures of several compounds dependent for oxygen on their own constituents and not on external sources. If the explosives were of identical chemical composition, as stated, then the only difference was the degree of mixing and physical structure of the constituents. The oxygen balance was presumably the same. It was possible that there might be noxious trace elements in the German explosives. Did the Authors investigate these aspects which should be capable of precise determination and would resolve the factors directly related to explosive manufacture?

75. Concentrations recorded by the Authors showed peak concentrations of $\mathrm{NO}_{2}$ half an hour or more after firing. One would have expected better diffusion and mixing with the velocities indicated. Traffic passing through fume plugs also helped with diffusion. On the works at Cruachan men were never allowed to work in fume plugs but might pass through them quickly, keeping the exposure to a minimum.

- Annual Reports, H.M. Chief Inspector of Mines, 1955-65. London, H.M.S.O. 
This required little supervision since it was always so unpleasant, and there was no inclination to remain in a foul plug.

76. Mr Hill's experience supported the Authors' view that forced ventilation into the face was usually the best method of getting quick re-entry after blasting. In long tunnels it was difficult to reverse fans if they were of the 'in line' type, spaced out down the fan duct. The attraction of this type of fan was that it was possible to get a large quantity of air through a comparatively small duct without having to get up to impractically high pressures. In most tunnels the problem to be faced was that of inadequate space for large enough air ducting and this was especially true of tunnels driven at high speed, consuming large quantities of explosives and using diesel-driven plant. Mr Hill hoped therefore that engineers designing tunnels would give adequate consideration to this aspect.

Mr C. A. Gillott (Civil Engineering Division (Home), The Cementation Co. Ltd) congratulated the Authors on providing such an interesting Paper on a difficult subject and one which involved fatal accidents.

78. It would appear that at the time of the tests the longer tunnels were of small cross-sectional area. It should be possible to use over-lap ventilation without undue problems being created. The Authors gave various reasons for not using this method.

(1) Attraction of diesel fumes to the face. These could be kept to permissible and harmless limits by using over-lap ventilation and fans of adequate size.

(2) An increase in temperature due to slow passage down the tunnel. This appeared to be inconsistent since the surface temperature was higher than rock temperature and the Authors claimed in $\$ 37$ that rock temperature governed air temperature.

(3) The inability to use fabric ducting. This was an important factor in the smaller headings.

(4) Heavy corrosion on the motors of axial flow fans. Bearing in mind the corrosive conditions existing at Seafield Colliery, Scotland, and the fact that the writer's company had very few breakdowns with a ventilation system using axial flow fans, even at a distance of almost three miles, it was felt that this was not the problem the Authors envisaged.

79. It was obvious from the report that:

(a) fumes could not be eliminated even by the water sprays;

(b) that they would always remain fatal;

(c) that the face area would remain safer due to the fact that this was the most efficiently ventilated part.

The only possible solutions would seem to be (i) to isolate the fumes from the tunnel by over-lap ventilation in preference to the reversible ventilation (which was not acceptable to the Authors), or (ii) to isolate the men from the fumes.

80. The latter solution could be effected by coupling-up a compressed air hose to an 'enclosed refuge' where the men could retire until such time as the plug containing the fumes had passed. This system was used very successfully in France where the men sat in a normal muck car, over which they placed a metal lid. This lid was coupled to the compressed air supply so that the 'covered box' in which the men sat was in fact a pressure chamber.

81. In relation to the standards of ventilation, Mr Gillott maintained that in high density mining, which was of course essential for tunnel driving, the quantity of air should be determined per square foot of face area, except where the number of men operating back-bye the face was excessive (in a small tunnel this was most unlikely): The Authors mentioned this fact in $\S 38$.

82. In conclusion Mr Gillott suggested that $\S 36$ was surely wrong in stating that the ventilation was satisfactory when fatalities resulted. 
Mr J. G. S. Hynd (Senior Civil Engineer, The Cementation Company Ltd) supported Mr Gillott and agreed that emphasis should be put on (a) isolating the fumes from the running section of the tunnel, where following-up work was in progress and where all the casualties occurred, or $(b)$ protecting the men from the fumes by the construction of 'enclosed refuges', either portable as in the example quoted by $\mathrm{Mr}$ Gillott, or at intervals along the tunnel.

84. The design of tunnel ventilation systems was influenced mostly by the two factors of economy and space. Although the writer's company were prepared to give a better air supply to the upper tunnel at their Blackwall contract, it was impossible to incorporate any larger size of duct than was installed. On the economy side, ventilation systems were designed on the general working conditions in the tunnel and not on the short period conditions after blasting.

85. With increase in tunnel length the conditions after blasting (in a forced ventilation system), although of a relatively short duration at any given location, existed at one point or another over most of the working period and in time over the full length of the tunnel, especially when blasting was taking place six times in every 24 hours. Therefore, the suggestion of 'enclosed refuges' coupled with a good communication system was one method of overcoming the problems of long tunnels with a forced ventilation system.

86. It was significant that the casualties at Cameron Highlands did not occur until some time after tunnel driving had begun, when losses due to length were obviously beginning to reduce the air supply and the speed of travel of the fume plugs.

87. In comparing Figs 1 to 6 , it might be stated that (a) the duration of the plug passing time was greater in the Habu tunnel than in the Telom or Woh tunnels; (b) the later tests carried out in the Woh tunnel (Figs 5 and 6) showed considerably smaller concentration than in the earlier tests. No positive reasons were given, but it was thought that the sampling point being further removed from the face and the slight changes in the drilling pattern might have had some influence.

88. Mr Hynd suggested that the Authors should have given more importance to the drilling pattern and pull achieved. If normal pull lengths were applied to the data on face area and weight of explosive per round given in Appendix 1, the results given in Table 3 were obtained. If the pulls chosen in Table 3 were near to those achieved in practice, the consumption of explosive per cubic yard for both the Telom and Woh tunnels was just below average for this type of blasting. This probably reflected on efficient blasting and also on the type of rock. However, the consumption in the Habu tunnel was very high. Unfortunately the Authors gave no information about the depth of round pulled or the drilling pattern employed. In addition to the weights of explosives given in Appendix 1 of the Paper, there was only one mention of drilling pattern. This was in $\S 3(\mathrm{~g})$ and it was assumed that this meant that the wedge cut was not used in any of the three tunnels under discussion. It would be interesting to have data on the drilling patterns and pulls achieved, especially if there was a higher casualty rate in the Habu tunnel.

89. If the figures in Appendix 1 were used to establish the average air velocity in the three tunnels, there was not much difference between the three (see Table 4 ).

TABLE 3

\begin{tabular}{l|c|c|c|c}
\hline & $\begin{array}{c}\text { Face } \\
\text { area } \\
s q . f t\end{array}$ & $\begin{array}{c}\text { Explosives } \\
\text { per round } \\
l b\end{array}$ & $\begin{array}{c}\text { Normal } \\
\text { pull } \\
f t\end{array}$ & $\begin{array}{c}\text { Explosives } \\
\text { per cu. yd. } \\
l b\end{array}$ \\
\hline Telom Tunnel & 87 & 75 & 6 & $3 \cdot 9$ \\
Habu Tunnel &. & 47 & 77 & 5 \\
Woh Tunnel & 225 & 260 & 11 & $\begin{array}{c}8 \cdot 8 \\
2 \cdot 8\end{array}$ \\
\hline
\end{tabular}


Despite this fact, as stated earlier, the duration of the plug passage in the Habu tunnel was longer than in the other two tunnels. It would be interesting to know if there was a greater number of casualties in the Habu tunnel per $1000 \mathrm{ft}$ of tunnel or per number of blasts than in either the Telom or Woh tunnels. If so, the evidence given above indicated a possible answer to the problem, although there was not sufficient data to be definite.

90. Mr Hynd's rule of thumb for tunnel ventilation was to have about $1 \mathrm{ft} / \mathrm{s}$ velocity of air in the tunnel. This was really a qualification on a face area basis for calculating requirements. In Great Britain more than $1 \mathrm{ft} / \mathrm{s}$ was felt to be too much ventilation and not so conducive to working. Applying this rule of thumb to the three tunnels the following figures were produced

Telom $\quad 87 \mathrm{sq} . \mathrm{ft}$ face area $\times 60$ secs $=5220 \mathrm{cu} . \mathrm{ft} / \mathrm{min}$

Habu . 47 sq. ft face area $\times 60 \mathrm{secs}=2820 \mathrm{cu} . \mathrm{ft} / \mathrm{min}$

Woh $\quad 225 \mathrm{sq}$. ft face area $\times 60 \mathrm{secs}=13500 \mathrm{cu} . \mathrm{ft} / \mathrm{min}$

91. From inspection of Table 2 these figures were not out of the way and, although other considerations must be included when calculating a tunnel ventilation system, it was a good check to produce a calculated result of between $\frac{3}{4}$ and $1 \frac{1}{4} \mathrm{ft} / \mathrm{s}$ air velocity in the tunnel.

TABLE 4

\begin{tabular}{|c|c|c|c|c|c|c|c|}
\hline \multirow[t]{2}{*}{ Tunnel } & \multicolumn{2}{|c|}{$1^{*}$} & \multicolumn{2}{|c|}{2} & \multirow{2}{*}{$\begin{array}{l}\text { Time when } \\
\text { concentration } \\
\text { reached } \\
100 \mathrm{ppm} \\
\text { min }\end{array}$} & \multirow{2}{*}{$\begin{array}{c}\text { Distance } \\
\text { from } \\
\text { face } \\
f t\end{array}$} & \multirow{2}{*}{$\begin{array}{l}\text { Velocity } \\
f t / s\end{array}$} \\
\hline & $\min$ & $p p m$ & $\min$ & $p p m$ & & & \\
\hline \multirow[t]{3}{*}{ Telom } & 10 & 87 & 15 & 320 & 11 & 1015 & $1 \cdot 54$ \\
\hline & 26 & 50 & 29 & 147 & $27 \cdot 5$ & 850 & 0.52 \\
\hline & 20 & 28 & 25 & 108 & $24 \cdot 5$ & 1000 & 0.68 \\
\hline Habu . . . & 88 & 71 & 95 & 75 & $\begin{array}{c}91 \cdot 5 \text { (near } \\
\text { to } \operatorname{maximum} \\
\mathrm{ppm})\end{array}$ & 4200 & 0.77 \\
\hline \multirow{6}{*}{$\begin{array}{l}\text { Woh (selection of } \\
\text { results only) }\end{array}$} & 9 & 60 & $12 \cdot 5$ & 234 & $9 \cdot 5$ & 775 & $1 \cdot 36$ \\
\hline & 12 & 41 & 14 & 232 & $12 \cdot 5$ & 775 & $1 \cdot 03$ \\
\hline & 19 & 98 & 21 & 166 & 19 & 1002 & 0.88 \\
\hline & 19 & 77 & 21 & 120 & 20 & 1044 & 0.87 \\
\hline & 23 & 60 & 24 & 126 & 23 & 1094 & $0 \cdot 80$ \\
\hline & 26 & 83 & 28 & 121 & 26 & 1178 & 0.76 \\
\hline
\end{tabular}

* The figures in columns 1 and 2 were taken from the Table in Appendix 1 to establish the time after blast when the concentration of the plug reached $100 \mathrm{ppm}$. This was adopted to give a common basis for calculating the velocities in the different tunnels. 
The Authors thanked all those who had contributed to the discussion. This confirmed that nitrogen dioxide poisoning was most unusual and the Authors had not succeeded in finding anybody with a comparable difficulty in civil engineering practice although in the Rand Gold Fields ${ }^{4}$ the same hazard had been reported. They were still unable to explain why nitrogen dioxide had been such a problem at Cameron Highlands and not elsewhere but they would certainly be very watchful on similar works in the tropics in the future.

93. Very early in their researches the Authors had come across the difficulty of comparing different subjective descriptions of the same thing. The difficulty was apparent in Table 1 and in the phrases quoted by Dr Wright in $\$ 46$ which were all taken from the references named. Similarly at the Cameron Highlands, what in the early days had been regarded as coughs and colds and chest complaints might in some cases have been the symptoms of mild nitrogen dioxide poisoning. This illustrated the difficulty of quoting for $\mathrm{Dr}$ Wright the total number of casualties or for $\mathrm{Mr}$ Hynd the number in each tunnel. As a matter of fact the majority of cases were reported from another tunnel, the Bertam tunnel, where experiments were impossible, and only a few were from the Telom tunnel. None were reported (to the best of the Authors' recollection) from either the $\mathrm{Habu}$ or Woh tunnels. This would also explain to Mr Gillott why the Authors could describe the ventilation in the Woh and Telom tunnels as satisfactory.

94. The Authors had no information on the chemical constituents of the explosives and could not answer Dr Wright's or Mr Hill's queries on this point. They were grateful to $\mathrm{Mr}$ Gurton for commenting that nitrogen dioxide was highly re-active which went some way to answering Dr Wright's question in $\S 61$. The theory that nitrogen dioxide might be occluded on dust particles which were subsequently filtered out in the nasal passages occurred to the Director of Chemistry in Malaya but a test showed that the quantities involved were insignificant.

95. In answer to Dr Wright, the calculations were based on the theoretical tunnel sections quoted in Appendix 2 and no correction was made for the different heights of the tunnels above sea level. These were additional reasons for treating the figures with caution when comparing them with statistics from other sources. The Authors did not think that for these rather crude experiments there was any advantage in working in terms of mass rather than volume.

96. The Authors agreed with Mr Lawrence that it was important to consider the distance of the sampling point from the face when comparing the amount of gas in one sample with another and that this should be borne in mind when considering Figs 1-6. Taking this into account they agreed that the conclusion reached in $\$ 3 \mathrm{e}$ and 16 might be misleading and that there was insufficient evidence to favour one type of explosive more than another. They found the use of ammonium nitrate/fuel oil explosives (ANFO) at Batang Padang most interesting and understood that it was proving to be cheaper than conventional explosives without adding to the ventilation costs. It also had the merit that the two constituents could be stored separately without such rigorous safety regulations.

97. Conditions in the field were so variable that it was impossible to take account of such factors as wetness and the quality of the stemming or of variations in the drilling pattern. In answer to $\mathrm{Mr}$ Hynd the Coromant cut was normally used; this was a type of burn cut developed by Atlas Copco of Sweden and the foreman in charge had discretion to vary the number and location of holes and their loading in the light of the joint pattern and condition of the face. The tunnel statistics published by Dickinson and Gerrard ${ }^{1}$ were average figures and were more reliable than those in Table 3 which assumed a larger pull than was generally achieved. The consumptions for the Habu tunnel were not considered excessive and it was fair to point out that in Appendix 2, Test 4, it was commented that the loading figure was suspect.

98. The ventilation standards given by the Authors in $\$ 38$ had not provoked any serious criticism and although slightly higher figures had been quoted by $\mathrm{Mr}$ 
Forster (for diesel plant only) Mr Hill and Mr Hynd, the Authors did not think that the differences were of any practical significance. Mr Forster's rule of thumb of $150 \mathrm{cu} . \mathrm{ft} / \mathrm{min}$ of free air per man was the exception because the Authors could say without any hesitation that ventilation at this rate would have been quite unacceptable in any tunnel on the Cameron Highlands. They inferred that the ventilation was at this rate in the Killin section of the Breadalbane project and as the ventilation was presumably satisfactory, the tropical conditions at Cameron Highlands, the longer heading at Telom and the composition of the blasting fumes were some possible factors which necessitated increased ventilation rates at the Cameron Highlands.

99. Mr Forster's success with an exhaust ventilation system was of interest although it did not appear to be favoured by any of the other contributors. The Authors still doubted if it was practicable in really long headings and themselves preferred a forced supply system. The overlap system suggested by Mr Gillott had obvious attractions and could be used with advantage in a system of caverns or tunnels served by two or more adits or headings but it obviously added to the costs, and in tunnels of small section there was often insufficient room for two ducts. It was an officer of the N.C.B. who had warned the Authors of the heavy corrosion suffered by the motors of axial flow fans when handling foul air, which was contrary to $\mathbf{M r}$ Gillott's experience at the Seafield Colliery.

100. In answer to $\mathrm{Mr}$ Hill, tests for both carbon dioxide and carbon monoxide were regularly carried out using a Draeger gas detector (sold in the U.K. by Normalair Ltd). The limitations of portable gas detectors with respect to nitrogen dioxide had been described in $\$ \$ 22-24$ but the Authors were unable to make the corresponding comparisons for carbon dioxide and carbon monoxide detectors. The measured concentrations were never found to be excessive even immediately adjacent to diesel machinery or when the atmosphere was thick with smoke. This latter condition sometimes led to complaints in the power station cavern where there was from time to time a concentration of small diesel units such as generators, air compressors and welding sets. In both the Telom and Woh tunnels the only diesel units were $40 \mathrm{hp}$ locomotives-one in the former and two in the latter, plus stand-by units-and all other plant including loaders was air- or electric-operated. In the bigger power station access and tailrace tunnels, diesel loaders and diesel dumpers were used, but there were never any ventilation difficulties. The Authors saw no evidence of a more than normal proportion of poor or incompletely combusted charges. 